\title{
Experimental viscosities and viscosity predictions of a ternary mixture comprising silicone oils and 1-octene from $293.15 \mathrm{~K}$ to $353.15 \mathrm{~K}$
}

Clémence Nikitine, Séverine Comba, Isabelle Pitault, Valérie Meille*

Université de Lyon, Institut de Chimie de Lyon, Laboratoire de Génie des Procédés

Catalytiques, CNRS, CPE Lyon, 43 bd du 11 novembre 1918, BP 82077, 69616

Villeurbanne cedex, France

\begin{abstract}
Viscosities of the ternary and binary of mixtures of 1-octene, Rhodorsil H68, Rhodorsil 308V750 have been measured at different temperatures between 293.15 and $353.15 \mathrm{~K}$ and at atmospheric pressure. Two correlations were established to predict the viscosity of all mixtures. The first is a statistical expression deduced from an experimental design. The second is based on an additivity law and the temperature effect on binary mixtures.

Key words: Hydrosilylation, Viscosity, Ternary mixture, Silicone oils, 1-octene
\end{abstract}

\section{Introduction}

Silicone waxes, i.e. polysiloxanes with a long alkyl chain $(>\mathrm{C} 8)$ as a pendant group make one of the most important classes of modified polysiloxanes widely used in different industrial applications. Main methods of silicone oil

\footnotetext{
*Corresponding author

Email address: vme@lgpc.cpe.fr (Valérie Meille)
} 


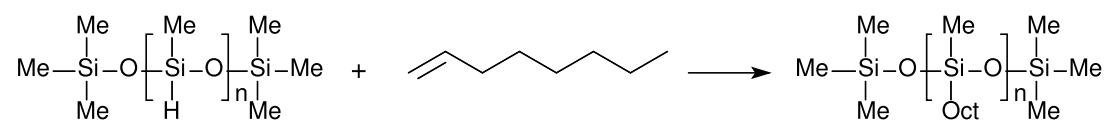

Figure 1: Hydrosilylation of 1-octene with Rhodorsil H68 (Me and Oct for methyl and octyl groups, $\mathrm{n} \approx 50$ )

synthesis are based on catalytic hydrosilylation of alkenes with poly(hydro, methyl)siloxanes [1]. Hydrosilylation is a catalytic reaction proceeding in the presence of free radical precursors or various catalysts, e.g. amines, Lewis acids (metal salts), supported metals and transition metal complexes [2]. One of the main problems of this reaction is the high viscosity of the product. Indeed, effluent viscosity has an impact on catalyst separation, mixing efficiency in batch reactors, flow and pressure drop in continuous systems. Hydrosilylation of 1-octene with the polymethylhydrogenosiloxane oil named Rhodorsil H68 $[3,4]$ is shown in Figure 1. The final product of the reaction is Rhodorsil 308V750 (called FP).

In order to design a safe process, mixture viscosity (octene $+\mathrm{H} 68+\mathrm{FP}$ ) at different conversions should be known. The viscosity of 1-octene being 4 orders of magnitude lower than that of the final silicone oil, the mixture viscosity varies in a wide range and is not easy to predict using published correlations because of the oil specificity. Classical correlations based on logarithmic additivity or group contributions [5] are not adapted to predict the viscosity of mixtures. In this work, we will report viscosities of pure components, and binary and ternary mixtures for different temperatures. Two correlations have thus been established to predict mixture viscosity. 
Table 1: Experimental densities of pure components at $298.15 \mathrm{~K}$ and comparison with literature data

\begin{tabular}{lcc}
\hline & \multicolumn{2}{c}{$\rho\left(\mathrm{kg} \cdot \mathrm{m}^{-3}\right)$} \\
\hline component & $\exp$ & litt \\
\hline octene & $710 \pm 5$ & $711.2^{a}$ \\
H68 & $992 \pm 8$ & $998^{b}$ \\
Final product & $903 \pm 4$ & $900^{b}$ \\
\hline$\left(^{a}\right)$ Prosim $[6]$ & $\left({ }^{b}\right)$ Supplier's data
\end{tabular}

\section{Experimental section}

The compounds used were 1-octene (98\%, Aldrich) and two silicone oils

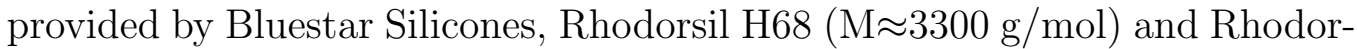
sil 308V750 ( $\mathrm{M} \approx 8400 \mathrm{~g} / \mathrm{mol})$. Purities of these compounds were checked by comparing the measured densities with those reported in the literature. To calculate the density, a $5 \mathrm{ml}$ volume of each compound was weighed (Mettler PM400). An average of 5 density measurements were carried out for each compound, in order to have precise results. Results are given in Table 1 and confirm the absence of other significant compounds.

Dynamic viscosity of pure compounds and their mixtures were determined using a Bohlin Gemini HR nano rheometer (Malvern Instruments), with a double gap (24/27) cell. The required volume of liquid is about $10 \mathrm{ml}$. The temperature was kept constant within $\pm 0.1 \mathrm{~K}$ by a Peltier system. Measurements were performed at a constant shear rate of $15 \mathrm{~s}^{-1}$. As a preliminary step, Newtonian behaviour was verified for all the compouds in a wide range of shear stresses. 


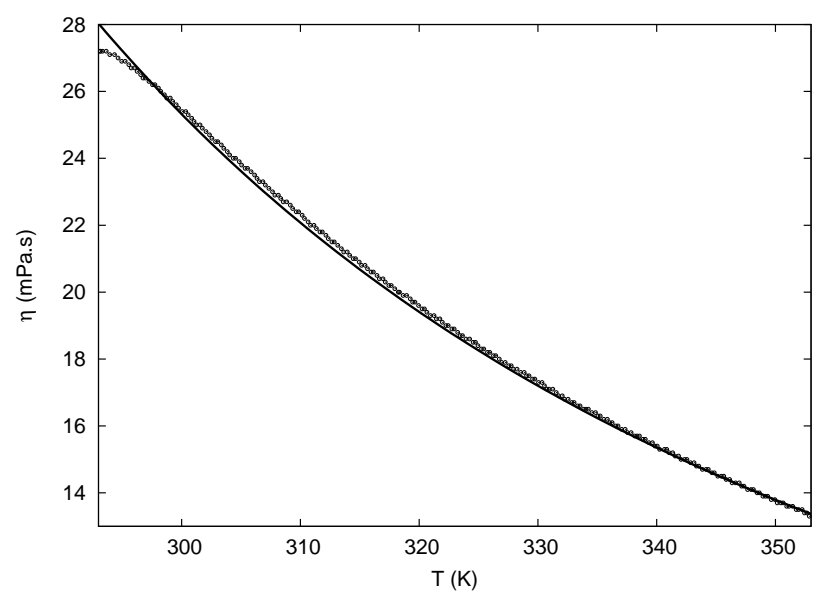

Figure 2: Viscosity of Rhodorsil H68 vs temperature - experimental data (०) and exponential law (solid line)

The mixture compositions are given in weight fraction and were determined by using a Mettler PM400 balance with a precision of $\pm 1 \mathrm{mg}$. Each prepared sample weighed $20 \mathrm{~g}$. The weight fraction precision is better than $\pm 4 * 10^{-3}$.

\section{Results and discussion}

Figures 2 and 3 show pure silicone oil viscosity versus temperature. For each component, the temperature effect can be represented by a classical correlation [7] for liquids (Equation 1).

$$
\eta=A \exp \frac{B}{T}(\text { with } \eta \text { in Pa.s })
$$

The coefficients $\mathrm{A}$ et $\mathrm{B}$ used to fit the experimental data in Figures 2 and 3 are reported in Table 2. For octene, these coefficients are the same as found in the literature [6]. For silicone oils, they are fitted using viscosity 


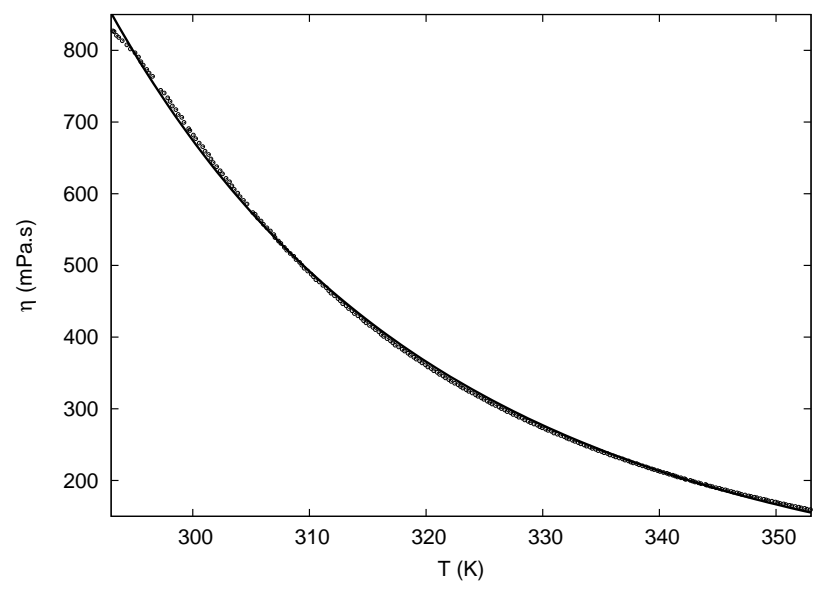

Figure 3: Viscosity of Rhodorsil 308V750 vs temperature - experimental data (०) and exponential law (solid line)

Table 2: Coefficients A and B for pure products

\begin{tabular}{ccc}
\hline product & $\mathrm{A}(\mathrm{Pa} . \mathrm{s})$ & $\mathrm{B}(\mathrm{K})$ \\
\hline octene & $1.67^{*} 10^{-5}$ & 982 \\
H68 & $3.6^{*} 10^{-4}$ & 1276 \\
$\mathrm{FP}$ & $3.79^{*} 10^{-5}$ & 2936 \\
\hline
\end{tabular}

measurements within the temperature range 293.15 - $353.15 \mathrm{~K}$.

Experimental viscosities of binary and ternary mixtures at $293.15 \mathrm{~K}$, 298.15 K, 303.15 K, 308.15 K are given in Table 3. The viscosity of the ternary mixture with low amounts of octene and final product and a high quantity of silicone oil H68 was not measured because these systems do not occur during the hydrosilylation reaction.

\subsection{Development of correlations}

In this study, two correlations have been established to represent the experimental results and thus predict the viscosity of a ternary (octene, Rhodor- 
Table 3: Experimental viscosities, $\eta$ (Pa.s) of binary and ternary mixtures at different temperatures; $w_{i}$ is the weight fraction of compound $\mathrm{i}$

\begin{tabular}{|c|c|c|c|c|c|c|c|c|}
\hline $\mathrm{w}_{H 68}$ & $\mathrm{w}_{\text {oct }}$ & $293.15 \mathrm{~K}$ & $298.15 \mathrm{~K}$ & $303.15 \mathrm{~K}$ & $308.15 \mathrm{~K}$ & $323.15 \mathrm{~K}$ & $338.15 \mathrm{~K}$ & \\
\hline 0.000 & 0.120 & $2.09 \mathrm{E}-01$ & $1.93 \mathrm{E}-01$ & $1.72 \mathrm{E}-01$ & $1.53 \mathrm{E}-01$ & - & - & (a) \\
\hline 0.000 & 0.694 & 3.71E-03 & $3.62 \mathrm{E}-03$ & $3.51 \mathrm{E}-03$ & $3.42 \mathrm{E}-03$ & $3.08 \mathrm{E}-03$ & - & (a) \\
\hline 0.000 & 0.822 & $1.62 \mathrm{E}-03$ & $1.57 \mathrm{E}-03$ & $1.51 \mathrm{E}-03$ & $1.47 \mathrm{E}-03$ & $1.33 \mathrm{E}-03$ & - & (a) \\
\hline 0.000 & 0.922 & $6.88 \mathrm{E}-04$ & $6.49 \mathrm{E}-04$ & $6.36 \mathrm{E}-04$ & $6.25 \mathrm{E}-04$ & $5.83 \mathrm{E}-04$ & - & (a) \\
\hline 0.000 & 0.101 & $2.50 \mathrm{E}-01$ & $2.24 \mathrm{E}-01$ & $1.98 \mathrm{E}-01$ & $1.74 \mathrm{E}-01$ & - & - & (b) \\
\hline 0.022 & 0.798 & 2.19E-03 & $2.09 \mathrm{E}-03$ & $1.95 \mathrm{E}-03$ & $1.82 \mathrm{E}-03$ & - & - & (b) \\
\hline 0.051 & 0.249 & $6.05 \mathrm{E}-02$ & $5.85 \mathrm{E}-02$ & & $5.12 \mathrm{E}-02$ & - & $3.20 \mathrm{E}-02$ & \\
\hline 0.052 & 0.330 & $2.01 \mathrm{E}-02$ & $3.25 \mathrm{E}-02$ & $3.06 \mathrm{E}-02$ & $2.88 \mathrm{E}-02$ & - & - & \\
\hline 0.080 & 0.699 & $1.03 \mathrm{E}-02$ & $2.74 \mathrm{E}-03$ & $2.57 \mathrm{E}-03$ & $2.46 \mathrm{E}-03$ & - & - & \\
\hline 0.109 & 0.452 & $1.41 \mathrm{E}-02$ & $1.37 \mathrm{E}-02$ & $1.29 \mathrm{E}-02$ & $1.23 \mathrm{E}-02$ & - & - & (b) \\
\hline 0.110 & 0.453 & $1.27 \mathrm{E}-02$ & $1.24 \mathrm{E}-02$ & $1.18 \mathrm{E}-02$ & $1.14 \mathrm{E}-02$ & - & - & (b) \\
\hline 0.110 & 0.449 & $1.28 \mathrm{E}-02$ & $1.22 \mathrm{E}-02$ & $1.16 \mathrm{E}-02$ & $1.10 \mathrm{E}-02$ & - & - & (b) \\
\hline 0.150 & 0.251 & $2.31 \mathrm{E}-02$ & $4.67 \mathrm{E}-02$ & $4.30 \mathrm{E}-02$ & $3.95 \mathrm{E}-02$ & - & - & \\
\hline 0.200 & 0.800 & $1.15 \mathrm{E}-03$ & $1.07 \mathrm{E}-03$ & $1.05 \mathrm{E}-03$ & $1.01 \mathrm{E}-03$ & - & - & $(a, b)$ \\
\hline 0.200 & 0.450 & $1.62 \mathrm{E}-02$ & $1.01 \mathrm{E}-02$ & $9.33 \mathrm{E}-03$ & $8.66 \mathrm{E}-03$ & - & - & \\
\hline 0.200 & 0.104 & $2.68 \mathrm{E}-01$ & $2.44 \mathrm{E}-01$ & $2.18 \mathrm{E}-01$ & $1.92 \mathrm{E}-01$ & - & - & (b) \\
\hline 0.202 & 0.096 & $2.76 \mathrm{E}-01$ & $2.53 \mathrm{E}-01$ & $2.25 \mathrm{E}-01$ & $1.99 \mathrm{E}-01$ & - & - & \\
\hline 0.299 & 0.451 & $1.61 \mathrm{E}-02$ & 8.57E-03 & $8.13 \mathrm{E}-03$ & $7.26 \mathrm{E}-03$ & - & - & \\
\hline 0.302 & 0.698 & $1.74 \mathrm{E}-03$ & $1.60 \mathrm{E}-03$ & $1.54 \mathrm{E}-03$ & $1.49 \mathrm{E}-03$ & - & - & $(a, b)$ \\
\hline 0.326 & 0.674 & $1.08 \mathrm{E}-02$ & $1.74 \mathrm{E}-03$ & $1.64 \mathrm{E}-03$ & $1.60 \mathrm{E}-03$ & - & - & (a) \\
\hline 0.368 & 0.632 & $1.17 \mathrm{E}-02$ & $2.11 \mathrm{E}-03$ & $2.02 \mathrm{E}-03$ & $1.93 \mathrm{E}-03$ & - & - & (a) \\
\hline 0.398 & 0.451 & $1.61 \mathrm{E}-02$ & $6.43 \mathrm{E}-03$ & $6.16 \mathrm{E}-03$ & $5.68 \mathrm{E}-03$ & - & - & \\
\hline 0.454 & 0.546 & $1.36 \mathrm{E}-02$ & $3.03 \mathrm{E}-03$ & $2.91 \mathrm{E}-03$ & $2.81 \mathrm{E}-03$ & - & - & (a) \\
\hline 0.506 & 0.000 & $1.60 \mathrm{E}-01$ & $1.40 \mathrm{E}-01$ & $1.29 \mathrm{E}-01$ & $1.22 \mathrm{E}-01$ & - & - & \\
\hline
\end{tabular}
(a) binary mixtures (octene/H68 or octene/FP)
(b) mixtures used for experimental design 
Table 4: coefficients $\mathrm{a}_{0}$ and $\mathrm{a}_{1}$ based on an experimental design

\begin{tabular}{ccc}
\hline $\mathrm{T}(\mathrm{K})$ & $\mathrm{a}_{0}$ & $\mathrm{a}_{1}$ \\
\hline 293.15 & $-0,78$ & $-7,34$ \\
298.15 & $-0,88$ & $-7,23$ \\
303.15 & -1 & $-7,14$ \\
308.15 & $-1,12$ & 7,03 \\
\hline
\end{tabular}

sil H68 and H308V750) mixture whatever the composition.

\subsubsection{First correlation}

The first correlation is based on the study of an experimental design. The mixtures used are noted (b) in Table 3. These mixtures could reflect the proportion of each component in different stages of the hydrosilylation reaction. The selected experimental design was a complete factorial design $2^{3}$. It was composed of 8 experiments, including 3 for reproducibility. They define the range of applicability of the design (Equation 2).

$$
0.1<w_{\text {oct }}<0.8 \text { and } 0.02<w_{H 68}<0.2
$$

The viscosity was determined using the equation :

$$
\ln \eta=a_{0}+a_{1} w_{\text {oct }}(\text { with } \eta \text { in Pa.s })
$$

Coefficients $\mathrm{a}_{0}$ and $\mathrm{a}_{1}$ were determined by resolution of a matrix equation using Matlab software. Different statistical tests, i.e. Fisher test and deviation minimisation $[8,9]$ were performed. The obtained coefficients are shown in Table 4. 
There is a linear evolution between the coefficients $a_{0}, a_{1}$ and the temperature. So, finally:

$$
\left\{\begin{array}{l}
\ln \eta=a_{0}+a_{1} w_{\text {oct }} \\
a_{0}=-2.29 * 10^{-2} T+5,93 \\
a_{1}=2.06 * 10^{-2} T-13,4 \quad(\text { with T in K) }
\end{array}\right.
$$

\subsubsection{Additive correlation}

The second method is simply based on the mixing rule (Equation 4):

$$
\eta_{m}(T)=\sum\left(x_{i} \cdot \eta_{i}(T)\right)
$$

where $\eta_{m}(T)$ is the predicted mixture viscosity at temperature $\mathrm{T}, \eta_{i}(T)$ represents the viscosity of each constituent at $\mathrm{T}$ and $x_{i}$ is the molar fraction of compound i. This equation is too simplistic and a measurable deviation is observed. Corrective factors, based on the octene molar fraction and temperature, have been obtained by analysing the binary mixtures octene-H68 and octene-FP (experiments (a) in Table 3). Binary viscosities can thus be calculated from Equations 5 and 6.

$$
\begin{gathered}
\eta_{o c t-H 68}=\eta_{m}(T) *\left[0.01 x_{o c t} T+\left(-47.41 x_{o c t}+45.66\right)\right] \\
\eta_{o c t-F H}=\eta_{m}(T) *\left[\left(-1.58 x_{o c t}+1.59\right) T+\left(443.617 x_{o c t}-446.0685\right)\right]
\end{gathered}
$$

Contributions from each of the binary viscosities given by Equations 5 and 6 are then used to determine the viscosity of the ternary mixture (Equation $7)$. 


$$
\eta_{\text {ternary }}=\frac{x_{H F}}{x_{H F}+x_{H 68}} * \eta_{o c t-F H}+\frac{x_{H 68}}{x_{H F}+x_{H 68}} * \eta_{o c t-H 68}
$$

\subsubsection{Validity of the correlations}

These two correlations have been used to estimate the viscosity for all data in Table 3. The ratio of experimental to predicted viscosity was calculated using Equation 8 and always gives a ratio higher than 1. This was chosen to give an easier graphical representation.

$$
\begin{aligned}
R_{\eta}=\frac{\eta_{\text {exp }}}{\eta_{\text {mod }}} & \text { if } & \eta_{\text {exp }}>\eta_{\text {mod }} \\
R_{\eta}=\frac{\eta_{\text {mod }}}{\eta_{\text {exp }}} & \text { if } & \eta_{\text {exp }}<\eta_{\text {mod }}
\end{aligned}
$$

Values of $R_{\eta}$ have been reported for all data in ternary diagrams (Figures 4 and 5). In these graphs, coordinates represent the mass fraction of each component and the point size is a function of the value of the ratio (see graphs' legend). For each point on Figures 4 and 5, there are several temperatures superimposed. We observe little difference in the ratio for the same ternary mixture as a function of temperature.

With the first correlation based on an experimental design, the ratio of experimental to calculated viscosity of the binary mixture (octene + Rhodorsil H68) is higher than 1.3 and is lower than 2.8. The latter value of the ratio is high, because these experiments are out of the range of applicability defined in Equation 2 and graphically represented in Figure 4. Moreover, for the binary mixture octene + silicone oil H68, the ratio decreases linearly when the octene mass fraction increases (Figure 6). The correlation used depends only 


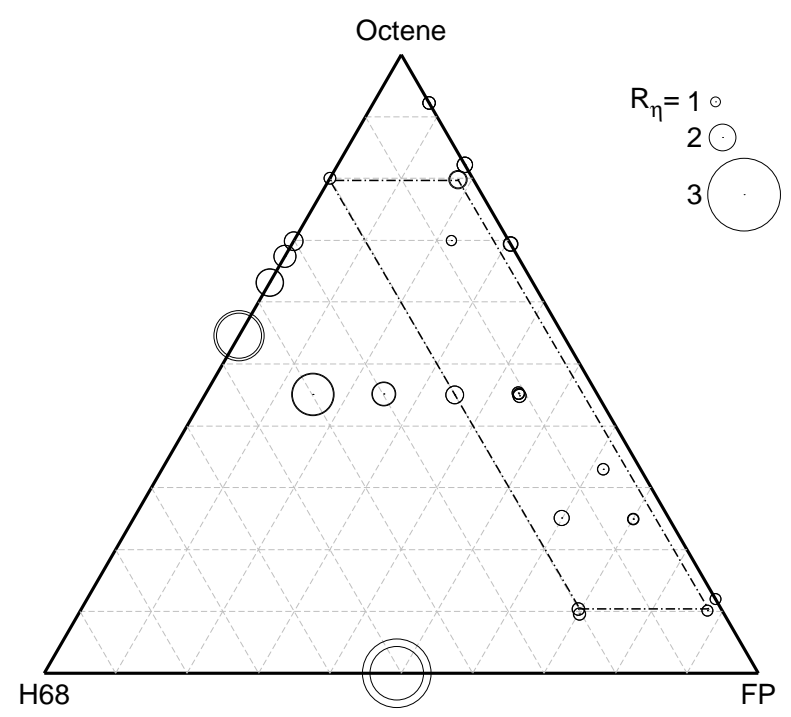

Figure 4: Ratio of experimental to calculated viscosity at different mass fraction with the first correlation - Validity zone in the dotted parallelogram

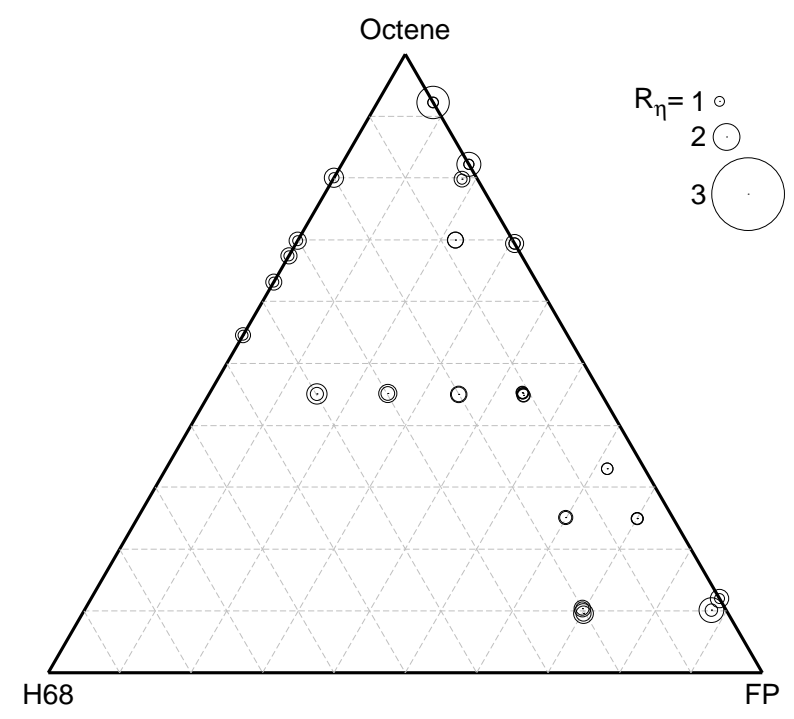

Figure 5: Ratio of experimental to calculated viscosity at different mass fraction with the second correlation 


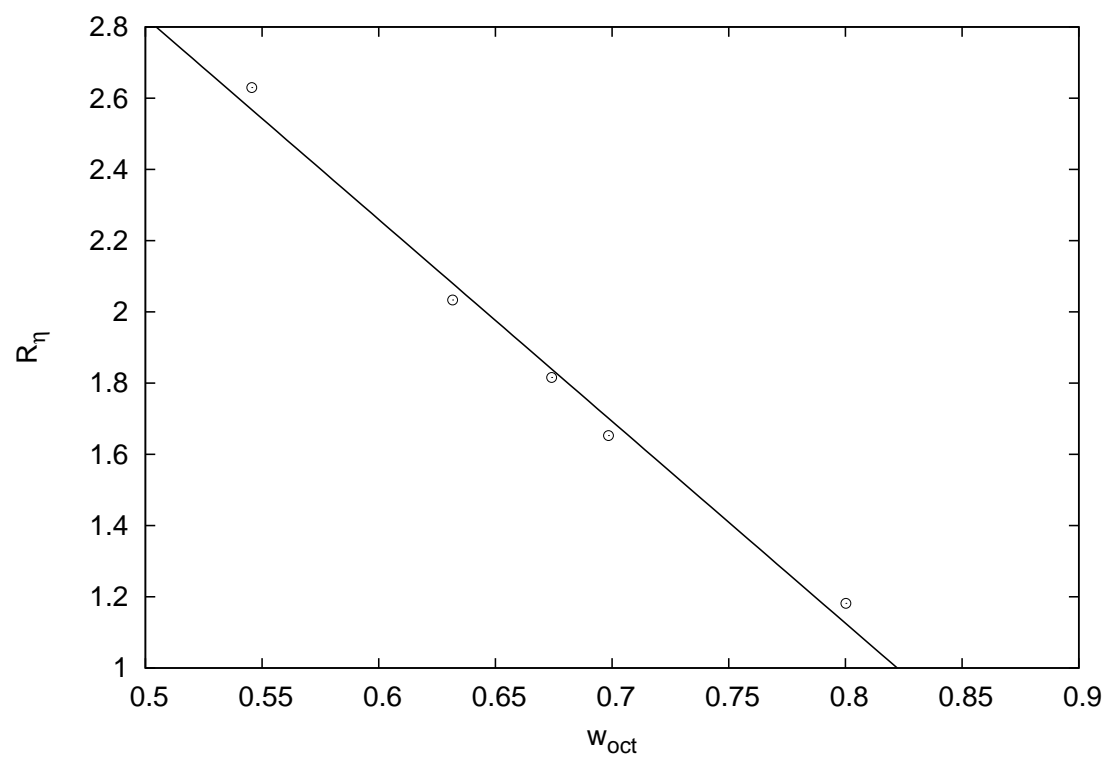

Figure 6: Evolution of the ratio of experimental to calculated viscosity with the octene mass fraction

on octene mass fraction which explains this phenomenon. Also, the viscosity of a mixture depends on molecular interactions between the components, thus, we can conclude that the binary mixture octene + silicone oil H68 is a system with weak interactions.

It is interesting to note that for the binary mixture (silicone oil H68 + final product), this correlation gives a good value of the viscosity (ratio between 1.2 and 1.4). These compositions are close to the applicability range and this system is a mixture with weak interactions.

Finally, within the applicability range of the correlation, the ratio of experimental to calculated viscosity is always lower than 1.5 .

Concerning the second model, the $R_{\eta}$ ratio is always lower than 2.2 showing a good accordance between experiments and calculations. However, the 
correlation is not able to predict the viscosity of the binary (Rhodorsil H68 $+\mathrm{FP})$ because the calculation is based on the octene molar fraction.

\subsection{Viscosity predictions}

Nine mixtures have been used for viscosity prediction. The first seven correspond to compositions potentially found during hydrosilylation reactions. Values obtained with both prediction correlations $(\bmod 1$ and $\bmod 2$ indexes in the Table) are reported in Table 5 for two temperatures. Experimental values are also given. The prediction is considered to be accurate enough for chemical engineering needs (values of $R_{\eta}<1.7$ ). The two last mixtures are outside the validity zone of both correlations but do not correspond to occuring mixtures during hydrosilylation. Moreover, these mixtures are not monophasic and a liquid-liquid separation occurs during viscosity measurements. These data are thus nor really relevant.

\section{Conclusions}

Experimental viscosities of mixtures composed of 1-octene, Rhodorsil H68 and Rhodorsil 308V750 have been measured at different temperatures between 293.15 and $353.15 \mathrm{~K}$ at atmospheric pressure.

Two correlations have been determined and ratios of experimental to predicted viscosities have been calculated. The first correlation based on an experimental design has shown that the binary systems were mixtures with weak interaction and that the octene mass fraction was the most significant parameter. The second correlation is based on a simple mixture law with corrections applied to each constituent binary mixture. 
Table 5: Prediction vs. experimental viscosities, $\eta$ (Pa.s) of binary and ternary mixtures at different temperatures

\begin{tabular}{cc|ccc|ccc} 
& & \multicolumn{3}{|c|}{$298.15 \mathrm{~K}$} & \multicolumn{3}{c}{$308.15 \mathrm{~K}$} \\
$\mathrm{w}_{H 68}$ & $\mathrm{w}_{\text {oct }}$ & $\eta_{\text {mod } 1}$ & $\eta_{\text {mod } 2}$ & $\eta_{\text {exp }}$ & $\eta_{\text {mod } 1}$ & $\eta_{\text {mod } 2}$ & $\eta_{\text {exp }}$ \\
\hline 0 & 0.45 & $1,56 \mathrm{E}-02$ & $1,15 \mathrm{E}-02$ & $1,53 \mathrm{E}-02$ & $1,36 \mathrm{E}-02$ & $8,40 \mathrm{E}-03$ & $1,38 \mathrm{E}-02$ \\
0.05 & 0.59 & $5,47 \mathrm{E}-03$ & $5,95 \mathrm{E}-03$ & $5,65 \mathrm{E}-03$ & $4,92 \mathrm{E}-03$ & $4,41 \mathrm{E}-03$ & $5,22 \mathrm{E}-03$ \\
0.07 & 0.63 & $4.33 \mathrm{E}-03$ & $5.73 \mathrm{E}-03$ & $3.85 \mathrm{E}-03$ & $3.91 \mathrm{E}-03$ & $5.69 \mathrm{E}-03$ & $3.46 \mathrm{E}-03$ \\
0.1 & 0.9 & $5,94 \mathrm{E}-04$ & $5,61 \mathrm{E}-04$ & $8,00 \mathrm{E}-04$ & $5,69 \mathrm{E}-04$ & $5,01 \mathrm{E}-04$ & $7,30 \mathrm{E}-04$ \\
0.13 & 0.37 & $2.89 \mathrm{E}-02$ & $2.45 \mathrm{E}-02$ & $2.31 \mathrm{E}-02$ & $2.47 \mathrm{E}-02$ & $2.31 \mathrm{E}-02$ & $1.98 \mathrm{E}-02$ \\
0.15 & 0.65 & $3,62 \mathrm{E}-03$ & $3,44 \mathrm{E}-03$ & $3,33 \mathrm{E}-03$ & $3,30 \mathrm{E}-03$ & $2,61 \mathrm{E}-03$ & $3,09 \mathrm{E}-03$ \\
0.23 & 0.57 & $6.79 \mathrm{E}-03$ & $7.41 \mathrm{E}-03$ & $4.41 \mathrm{E}-03$ & $6.05 \mathrm{E}-03$ & $5.05 \mathrm{E}-03$ & $4.08 \mathrm{E}-03$ \\
0.35 & 0.25 & $3,33 \mathrm{E}-02$ & $1,50 \mathrm{E}-02$ & $1,59 \mathrm{E}-02$ & $2,31 \mathrm{E}-02$ & $1,11 \mathrm{E}-02$ & $1,44 \mathrm{E}-02$ \\
0.8 & 0.1 & $1,94 \mathrm{E}-01$ & $1,35 \mathrm{E}-02$ & $2,96 \mathrm{E}-02$ & $1,58 \mathrm{E}-01$ & $1,07 \mathrm{E}-02$ & $2,65 \mathrm{E}-02$ \\
\hline
\end{tabular}


The viscosity prediction is not extremely precise but, within the operating conditions used for hydrosilylation, allows a rough estimation of the mixture viscosity at different conversions. The first correlation should be preferred within its validity zone whereas the second gives good estimations as long as the mixtures are monophasic.

\section{Acknowledgements}

This research was supported by ANR (French National Research Agency).

\section{References}

[1] B. Marciniec (Ed.), Comprehensive Handbook on hydrosilylation, Pergamon, 1992.

[2] B. Marciniec, J. Gulinski, H. Maciejewski, Encyclopedia of Catalysis, Vol. 4, Wiley, Hoboken, 2003.

[3] C. Fischer, G. Mignani, C. Priou, Functionalized inorganic oxide hydroxylated carrier and method for preparing same, US patent 6132874 (US6132874).

[4] S. Breunig, P. Olier, Lubricating polyrganosiloxane oil, aqueous emulsion containing same, preparation and use thereof for stripping metals, US patent 20040024162 (US20040024162).

[5] R. C. Reid, J. M. Prausnitz, B. E. Poling, The properties of gases \& liquids - 4th edition, Vol. p. 474, McGraw-Hill, Inc., 1987. 
[6] Prosimplus software version 3.0 / copyright 1998-2009, http://www.prosim.net.

[7] R. C. Reid, J. M. Prausnitz, B. E. Poling, The properties of gases \& liquids - 4th edition, Vol. p. 439, McGraw-Hill, Inc., 1987.

[8] J. Goupy, Plans d'expériences, Techniques de l'ingénieur, Traité Analyse et Caractérisation, Vol. PE 230, pp 1-26, 1997.

[9] J. Goupy, Plans d'expériences pour surfaces de réponse, Vol. chap7, pp 117-138, Dunod, 1999. 